\title{
Piles funéraires gallo-romaines du Sud-Ouest
}

Ariège, Gers, Haute-Garonne

\section{(2) OpenEdition}

Journals

Édition électronique

URL : http://journals.openedition.org/adlfi/10878

ISSN : 2114-0502

Éditeur

Ministère de la Culture

Référence électronique

"Piles funéraires gallo-romaines du Sud-Ouest », ADLFI. Archéologie de la France - Informations [En ligne], Midi-Pyrénées, mis en ligne le 01 mars 1997, consulté le 14 novembre 2019. URL : http:// journals.openedition.org/adlfi/10878

Ce document a été généré automatiquement le 14 novembre 2019.

(c) Ministère de la Culture et de la Communication, CNRS 


\title{
Piles funéraires gallo-romaines du Sud-Ouest
}

\author{
Ariège, Gers, Haute-Garonne
}

Date de l'opération : 1991 (PT)

Inventeur(s) : Soukiassian Georges

1 Cette prospection thématique concernant l'étude des piles funéraires gallo-romaines du Sud-Ouest, provient d'une initiative du service régional de l'Archéologie de MidiPyrénées qui, au travers d'un échange de chercheur avec l'Institut français d'Archéologie orientale (IFAO), devrait permettre de mener une réflexion d'ensemble sur ce type particulier de monument.

2 D'ores et déjà, on peut constater que ces piles monumentales n'ont fait l'objet d'aucune perspective de recherche à long terme, alors même que les potentialités étaient grandes et que les données déjà acquises lors des fouilles encore inédites des deux piles de Mirande dans le Gers (Gallia, 1970 : 419) auraient pu servir de base pour étayer une telle problématique. C'est pour cela que les campagnes de relevés entreprises dans les années soixante par J. Lauffray (Bureau d'Architecture antique du sud-ouest, CNRS) ont été fécondes d'autant plus qu'elles étaient couplées avec certaines interventions archéologiques qui ont permis de déterminer des caractéristiques propres (par exemple, la présence d'enclos).

3 En sommeil depuis plus de vingt ans, ce dossier a été repris au cours de la campagne de 1991 avec pour objectif de reprendre la documentation existante, d'établir une hiérarchie sur les possibilités de fouilles et de réfléchir à une véritable problématique de recherche où tous les aspects de l'environnement des piles pouvaient être intégrés (proximité des voies et d'établissements ruraux, etc.).

4 Un premier recensement permet de réactualiser l'inventaire de Lauzun (1898) et de déterminer l'existence de quinze piles :

5 Leur étude architecturale est déjà bien avancée avec des propositions de restitution (Gallia , 1968 : 540, fig. 26) qui permettront de définir une typologie. 
6 Il reste à établir une chronologie basée, autant sur des critères architecturaux que sur des données de fouilles, à situer le groupe de piles du sud-ouest de la Gaule dans l'histoire de l'architecture funéraire du monde romain.

7 Cette opération, dont l'ambition était limitée à une simple mise à plat des connaissances, n'est que le prélude à un programme collectif de recherche dont le terme devrait voir aboutir un projet de publication, de protection et de mise en valeur de ces monuments.

INDEX

Index chronologique : Antiquité romaine

operation Prospection thématique (PRT) 